\title{
دور فن النحت في تربية الذوق الجمالي
}

\author{
إعلداد \\ د/ئوسف ناصر المليفحــ \\ باحث من دولة الكويت
}

مجلة بحوث التربية النوعية ـ جامعة المنصورة

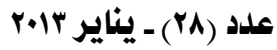




\section{دور فن النحت في تربية الذوق الجمالي}

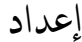

د دوسف ناصر المليفيخـ

الاقدهمة

ترتبـ الفنـون بـالمجتهـع مـن حيـث أنها تعكس، وتعبر عن السهـات النوعيـة لفئـات اجتمهاعيـة

معينة يْ زمن معين.

وبذلك يتحرك الـذوق الجمـالي على أرضـيـة التـاريخ ... مـن خـلال أنـه يـرتبط ارتبـاطـا وثيقـا

ببــى فوقيـة ايدولوجيـة وبنـى تحتيـة اقتصدادية..." وتتعلـق كل ابنـى الفقيـة الايدولوجيـة ـ وفق هـذه الرؤيسة .بـالظروف الاقتهـادية ( وسـائل الإنتـاج وعلاقـات الإنتـاج) . ومـن بـين تلـك (البنـى الفوقيـة

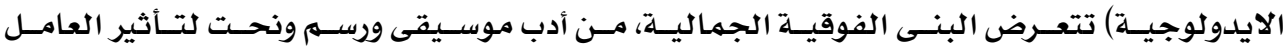
الاقتصادي بصورة غير مباشرة وعلى نحو بالتغ التعقيد"' .

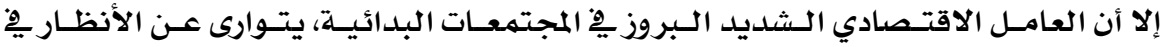
المجتمعات المتفاوتة التطور ويحتجب خلف العامل السيكولوجي الاجتمـاعي... حيـث لا سبيل لدراسـة

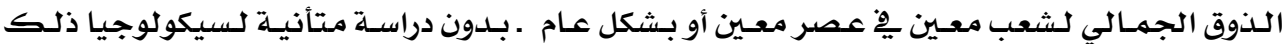
المجتهـع بطبقاته الاجتهماعيلة المختلفـة وما يـلدور بينها مـن صـراعات تـؤثر على الايـدولوجيات وتتجلى مِ2 تشكيلاته.

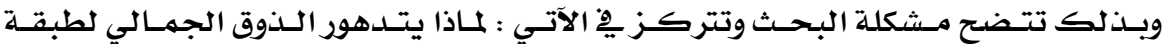
اجـتماعيـة معينـة حـين تؤول هـذه الطبقــة ذاتها إلى الأفـول... حيـث أن رقي الـذوق الجمــالي وتطـوره يتطلب تقدما وتطورا أيضا على المستوى الاجتهماعي. ولما كان هذا البحث يتعلق بلدراسـة دور النحست يِّ تربيـة الذذوق الجمـالي، ثم الإثـارة إلى دور

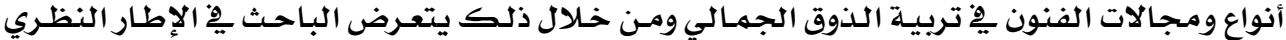
للبحثث إلى الخصائص الجهمالية التي تميز بها فن النحـت دون غيره مـن الفنـون بمـا يجعلـه متفـردا ... ثم الولـوج إلى نظريـة التتلقي لتوضـيح كيفيـة تلقـي فن النحست وبالتـالي التوصل إلى الـدور الفاعل

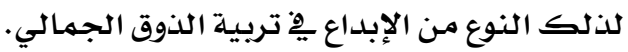




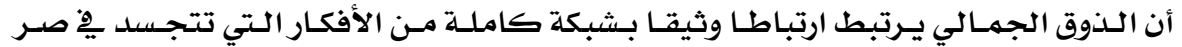
ومجلات الفنن الإبداعية المختلفة.

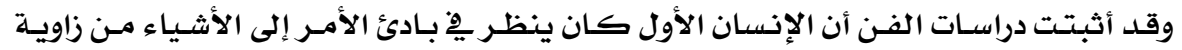

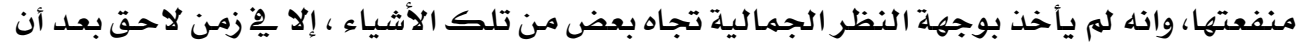

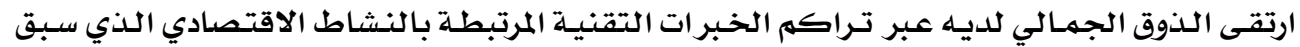

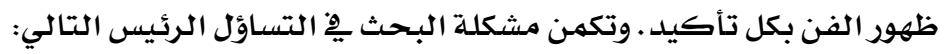
كيف يمكن لفن النحت أن يؤدي إلى تريية الذوق الجماليء هدف البحث 1- الكثف عن إمكانية وفاعلية وقدرة فن النحت يِّ تربية الذوق الجمالي. r - معرفة الدور الهام والحقيقي لفن النحت باعتباره أحد مجالات الفنون الإبداعية. r- تربية وتنمية الذوق الجمالي لدي المشاهد بشكل عام.

فرض البحث يفترض الباحث أن : يوجد دور لفن النحت ِِِ تربية الذوق الجمالي.

\section{هدود البمث}

يتعرض الباحث لمختارات من الأعمال الفنية من الحضارات والمدارس الفنية المختخلفة (بشكل

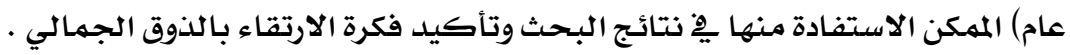
هنهمج البمث يعتمد البحث على المنهج الوصفي التحليلي باعتباره انسب المناهج لدراسـة وتحليل الأعمـال الفنية وكذلك لدراسة مشكلة البحث والتوصل إلى نتائج علمية. الإطار النظري لابمث: أولا: تعريف الذوق الجمالي:

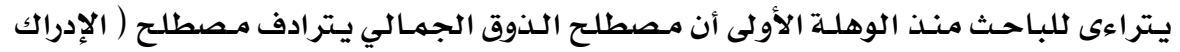

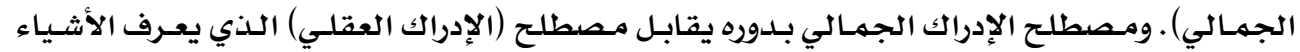
كما هي عليه يِّ الواقع (كحقائق). 


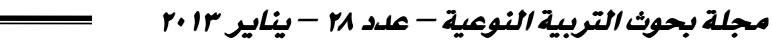

أما الإدراك الجمالي فهو (إدراك حسي نقدي) يلتق ما يِّ الأثياء من قيم، ... والقيم نوعان :

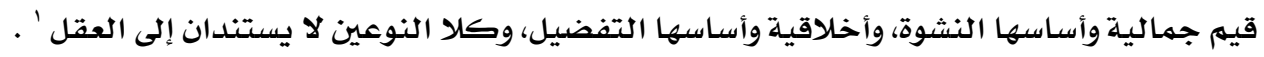

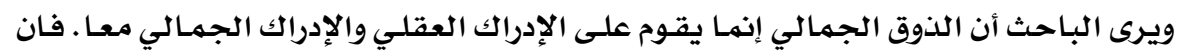

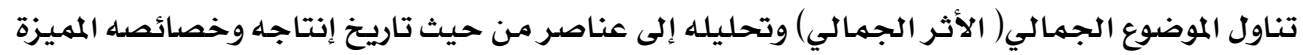

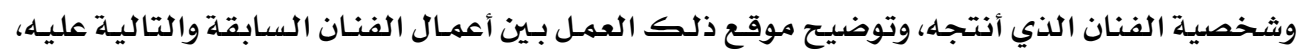

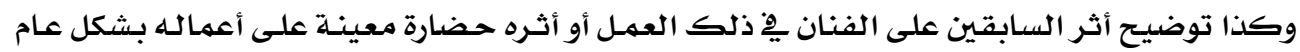

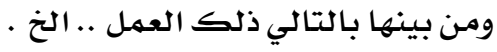

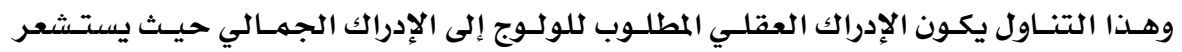

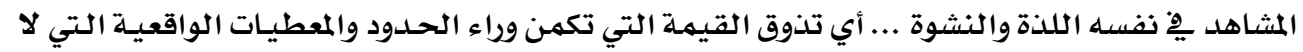

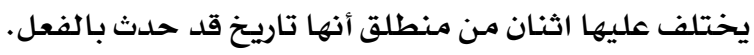

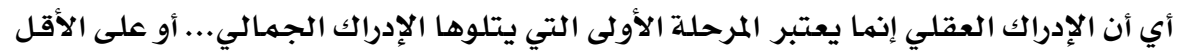

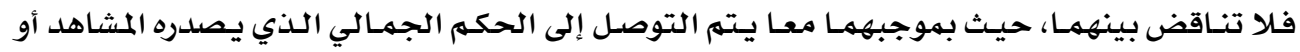

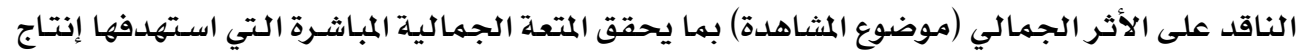
الموضوع الجمالي يُ البداية.

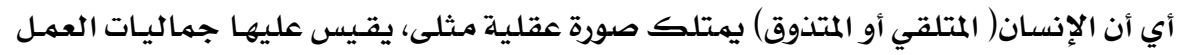

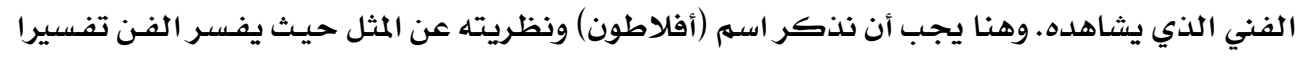

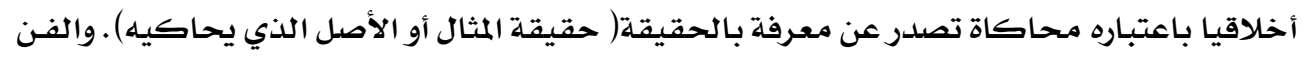

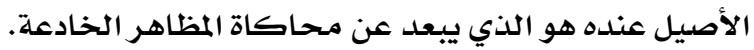

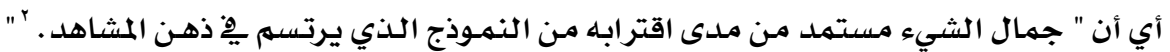

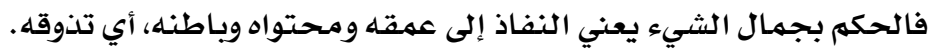

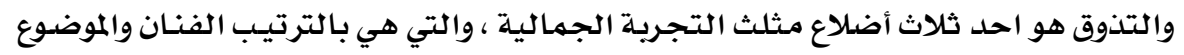

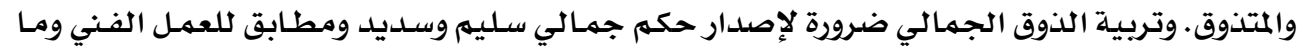

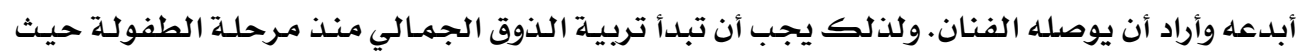

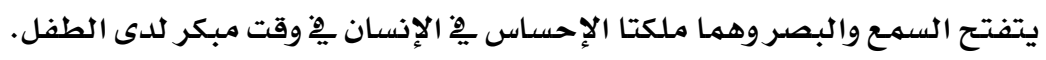

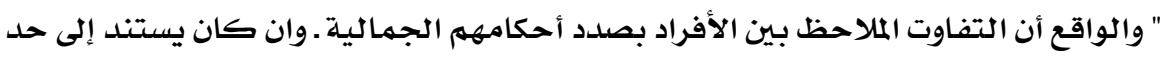

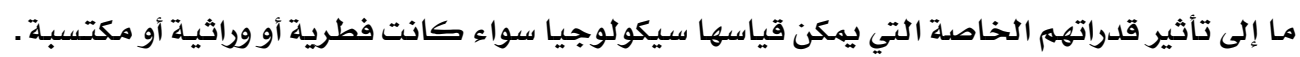

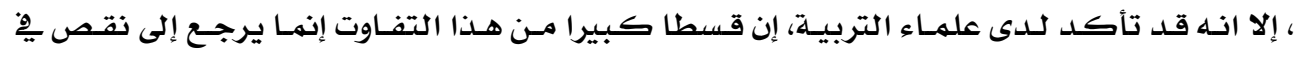

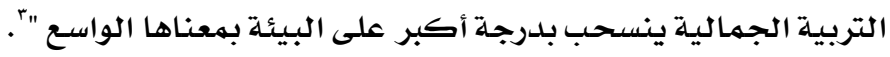




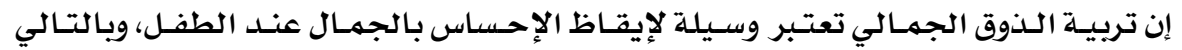

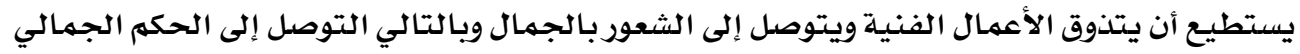

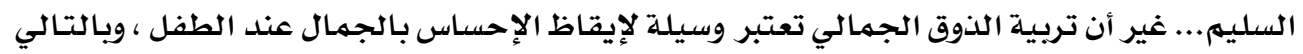

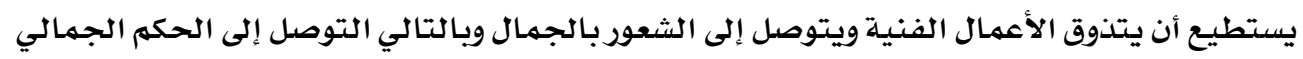

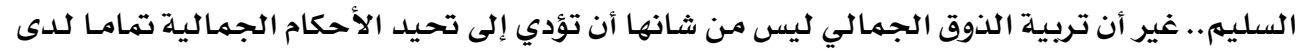

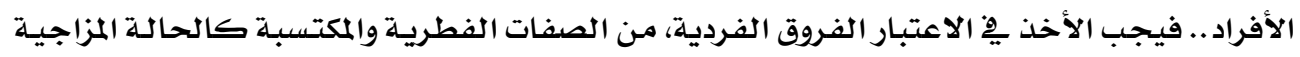

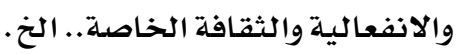

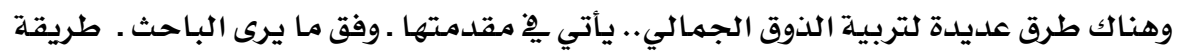

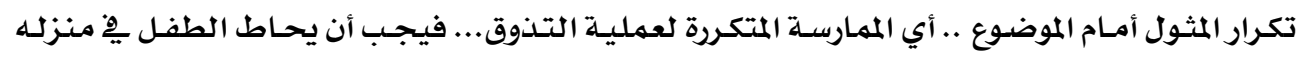

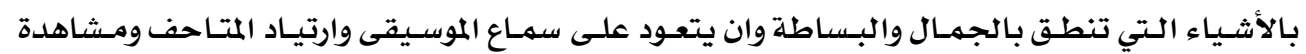

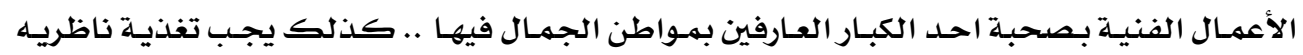

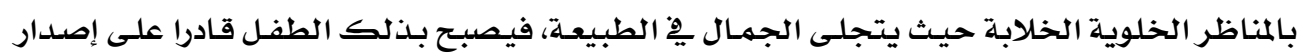
أحكام جمالية سوية تقوم على إدراك متكامل لمعنى الجمال من خلال تراكم الخبر الجات الجمال الجمالية.

\section{ثانياً: دور الفز في تربية الذوق الجمالي:}

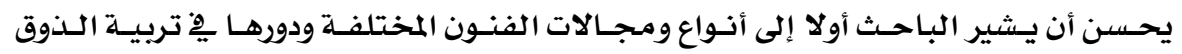

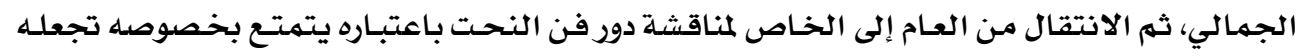

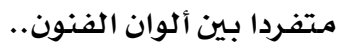

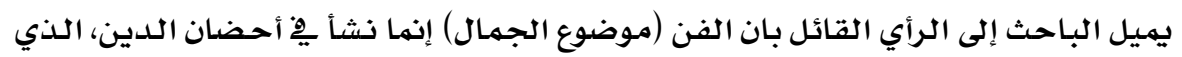

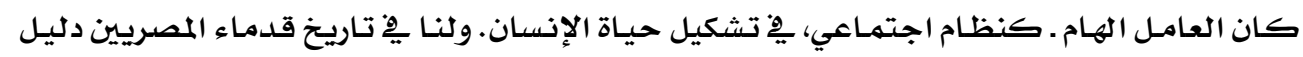

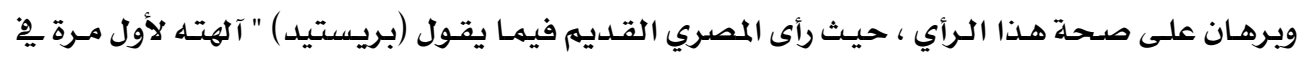

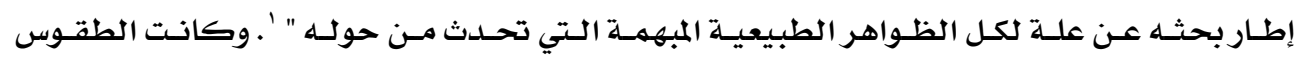

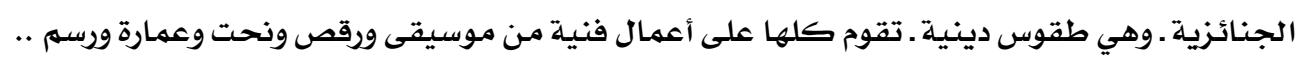

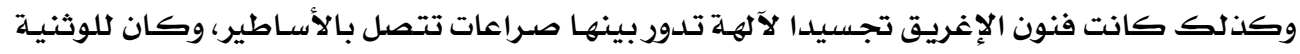

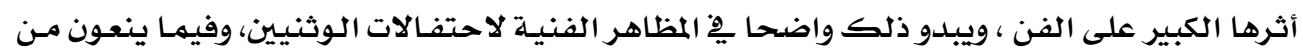

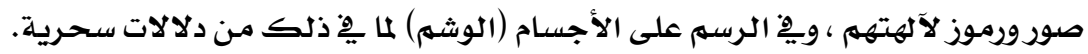

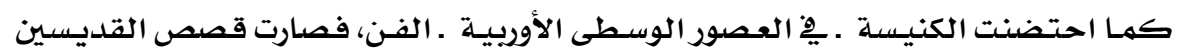

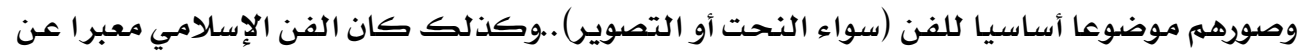

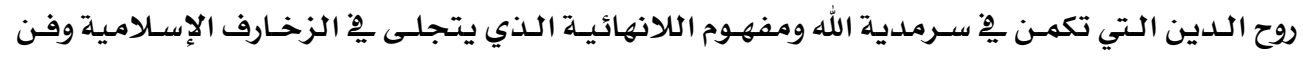

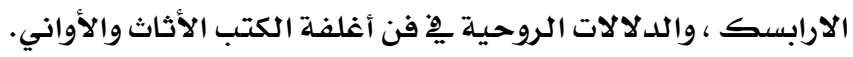


$\underline{\underline{ }}$

قد استفادت الأديان جميعها - بالفنون ـ كوسيلة سهلة للوصول على عقل وقلب الجمهور.

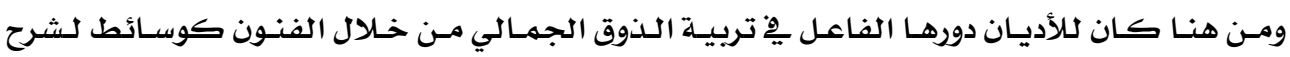

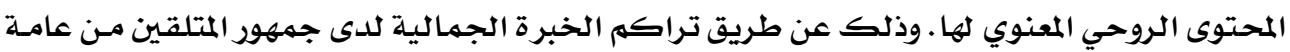

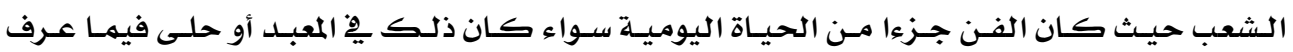
بالفنون الدقيقة.

وِِّ إطـار التربيـة الجماليـة يـرى الباحـث أن المعابـ (ودور العبـادة عمومـا ) مـن كنـائس وأديـرة

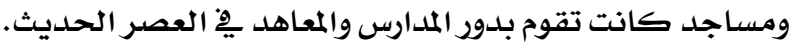

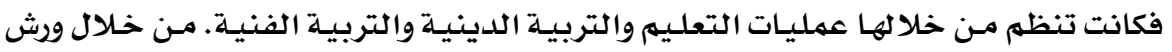

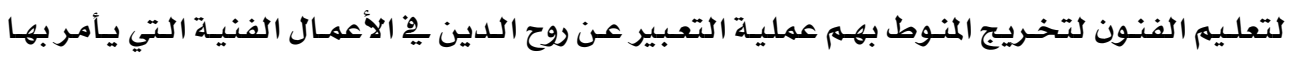
الكهنة ورجال الدين.

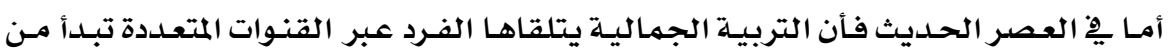

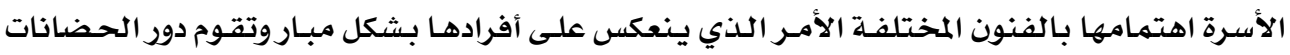

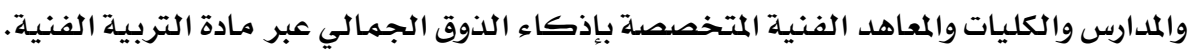

وكذلك الأنشطة الأخرى التي يمارسها الطلاب بالكليات غير المتخصصـة بالجامعات .

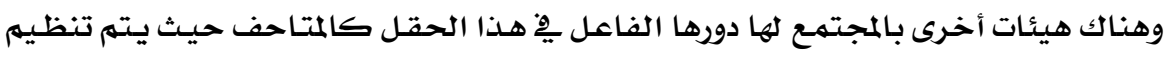

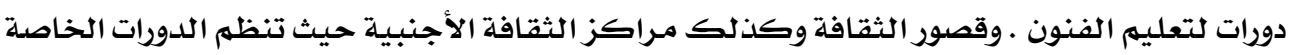

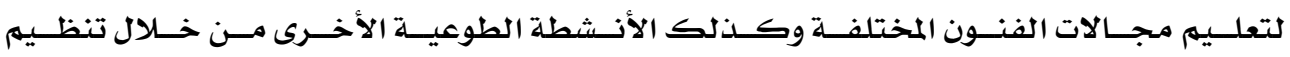
المعارض العامـة.

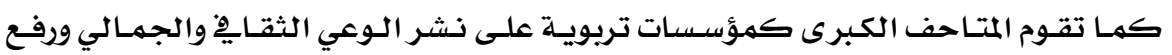

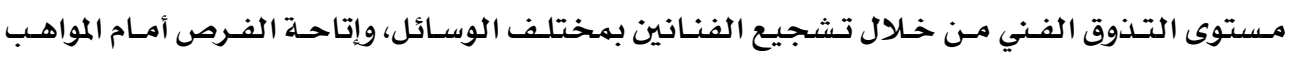

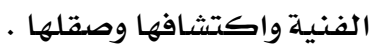

\section{ثالثا: الخصائص الجمالية لفن النحت ودوره في تربية الذوق الجمالي:}

نشأ النحت مـع الإنسان بعد أن بلدأت الحياة الإنسانية تستقر وأخذ الإنسان يبحث لنفسـه عن

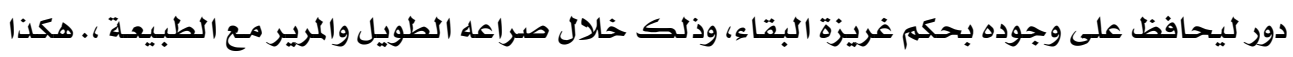

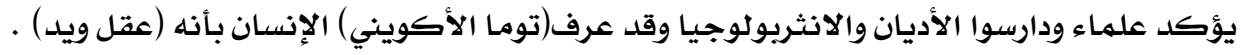

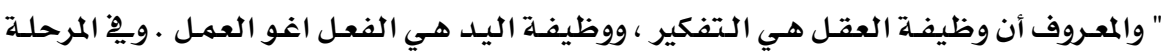

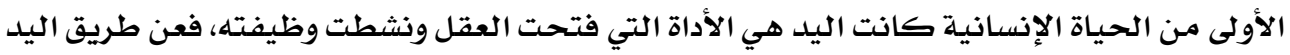

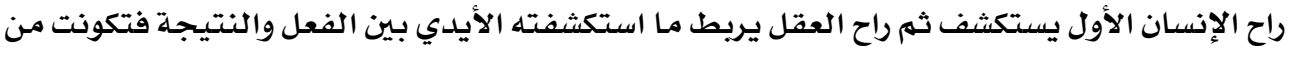

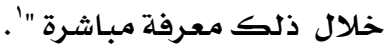




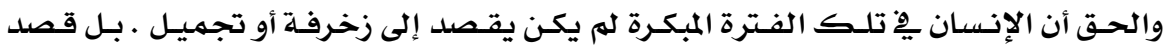

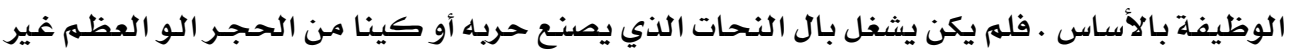

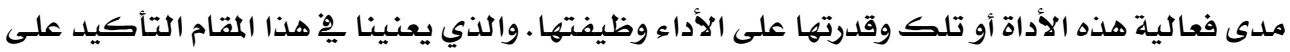

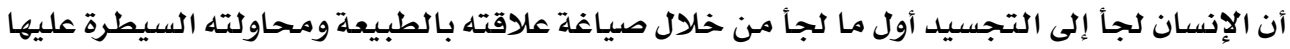

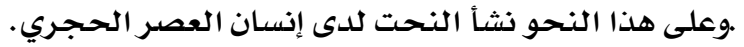

وحين خطى ذلك الإنسان إلى تعارف الوجود واكتشف الزراعة كانت قد ظهرت الأسطورة

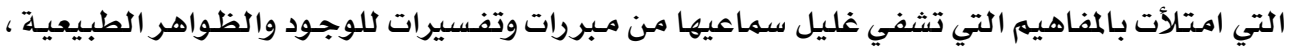

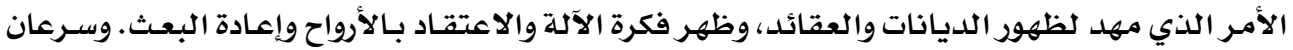

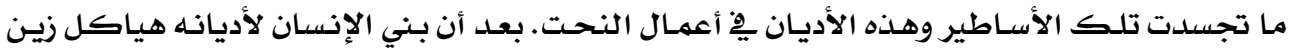

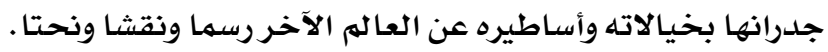
وهنا انتقل النحت من مجردد صنـع لأدوات الصيد والأسلحة إلى أن يصبح ذو مضمون. ثم تطورت أسـاليب النحست واتجاهاته مـع تطور الحيـاة الإنسانية لتتلاءم ذلك مـع ظروف

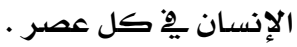

حيـث لم يعـد النحست فِ العصور الحديثـة انعكاسـا للعقائـد الدينيـة والأوضـاع الاجتماعيـة

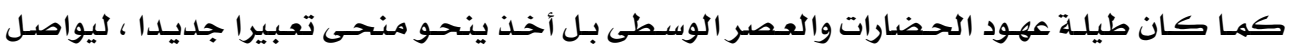

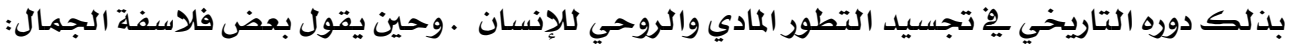

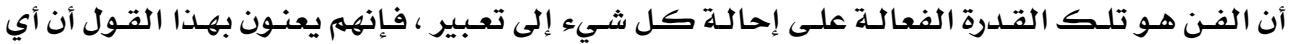

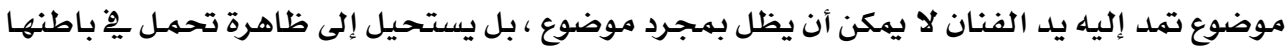

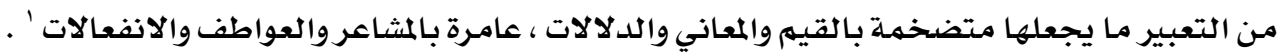

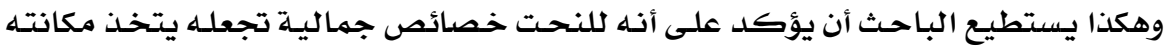

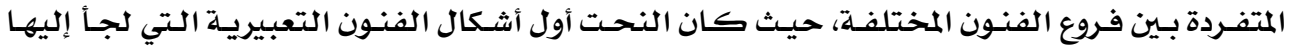

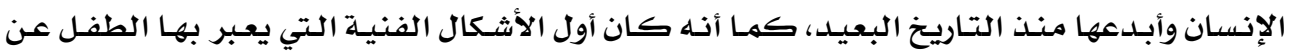

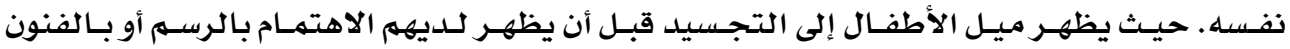

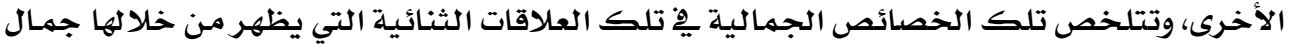

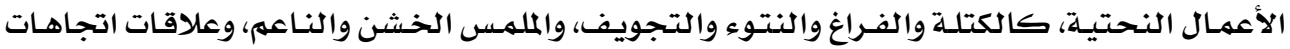

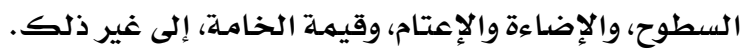

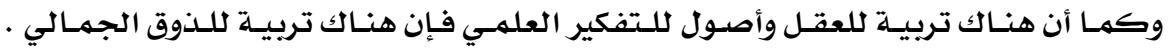

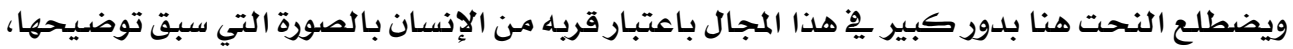

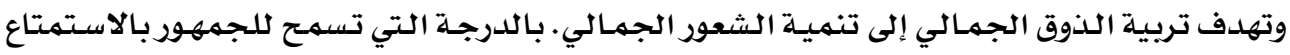

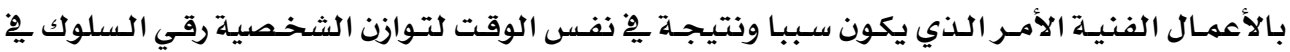


عملية جدلية متنامية باضطراد، تتم يْ تواز مـع عملية النهم العقلي وتطور التفكير " بحيث أن ما يؤثر

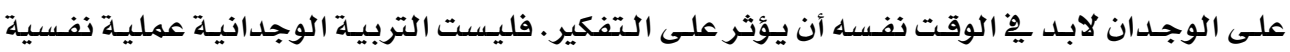

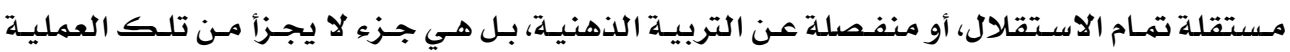

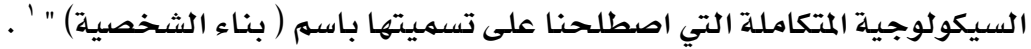

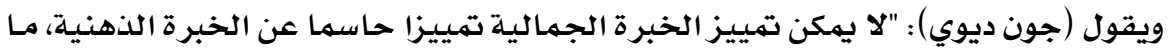

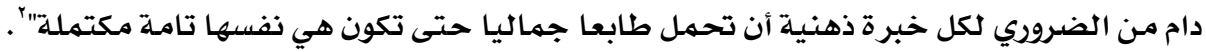

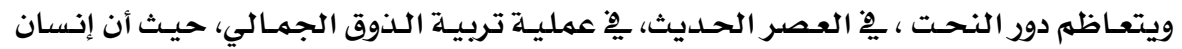

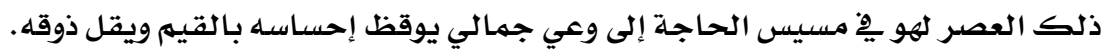

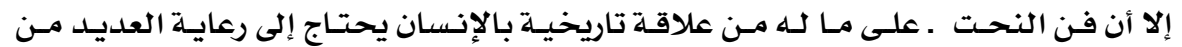

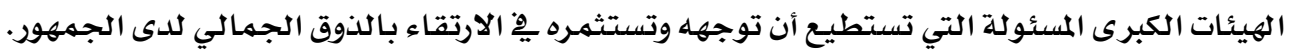

\section{ويقصد الباحث بذلك عدة أمور يأتي يِّ مقدمتها:}

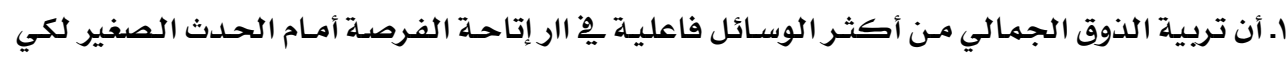

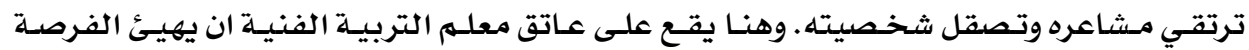

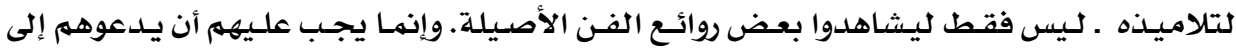

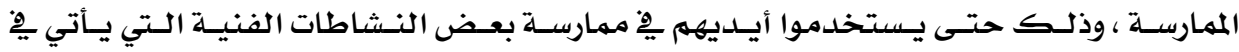

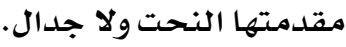

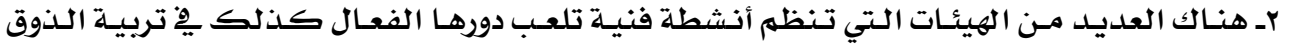

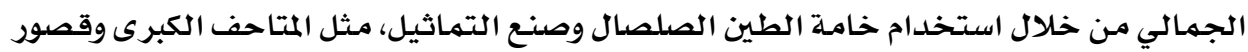
الثقافة والمكتبات المركزية.

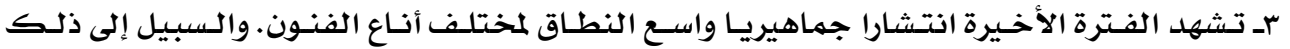

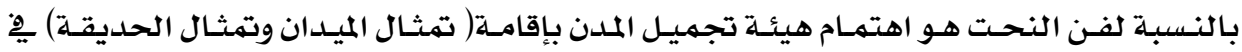

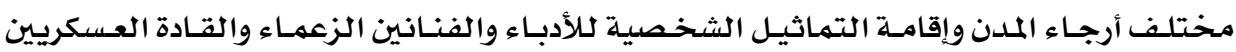

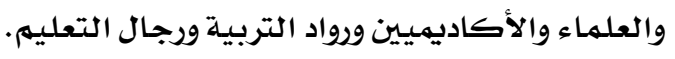

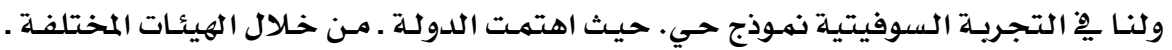

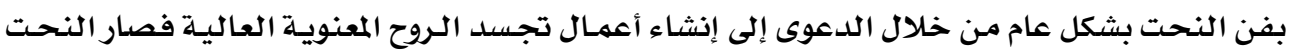

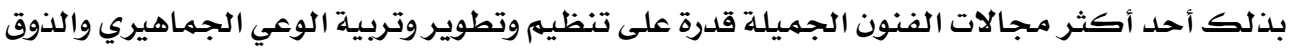

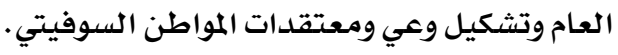

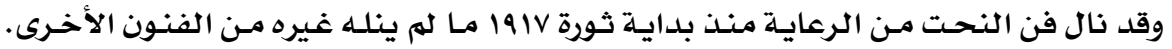

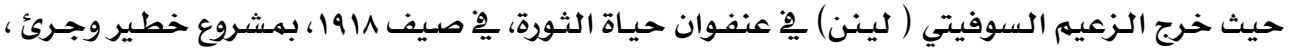




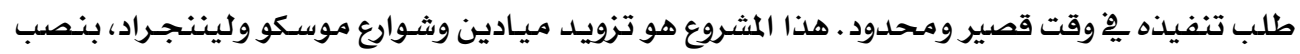

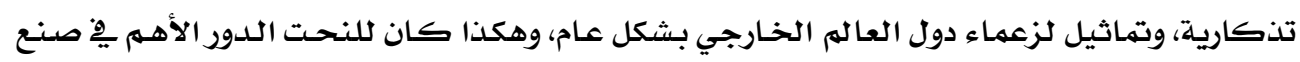
الإنسان الجديد.

رابعا: كيفية تلقي النحت:

\section{(نظرية التلقي - جمالية التلقي)}

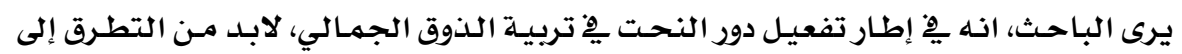

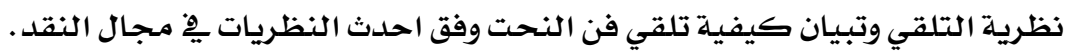

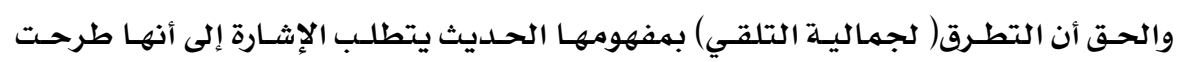

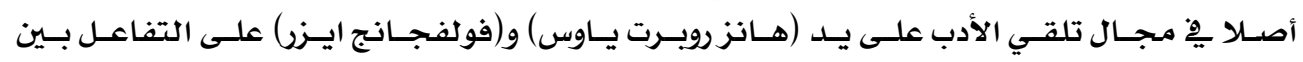
المبدع والجمهور.

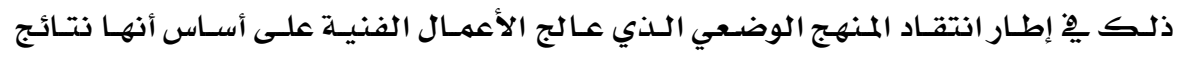

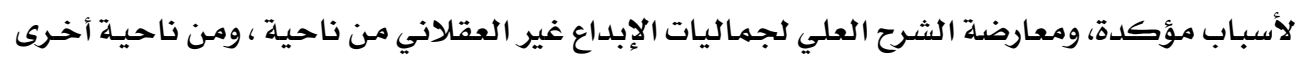

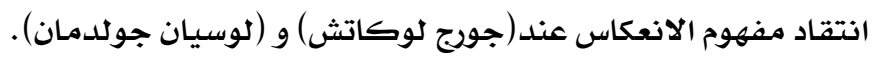

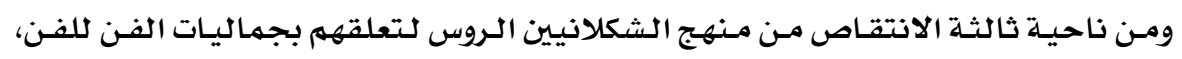
وعدم قدرتهم على الربط بين تطور الفنون والتطورات التاريخية الأعم.

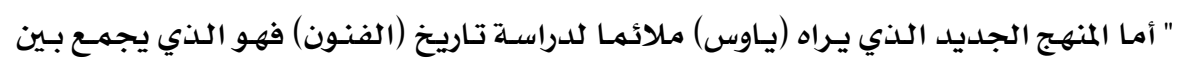

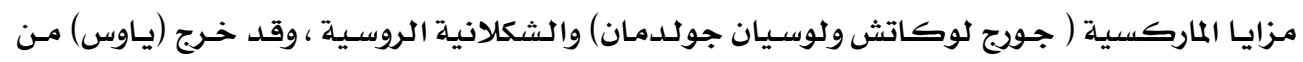

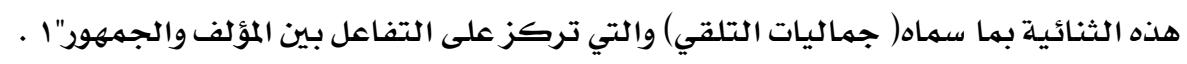

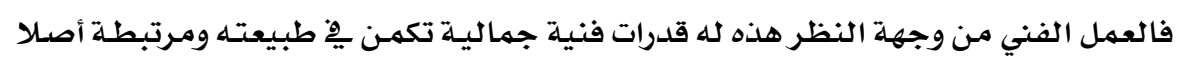

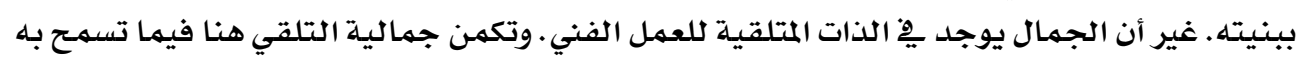

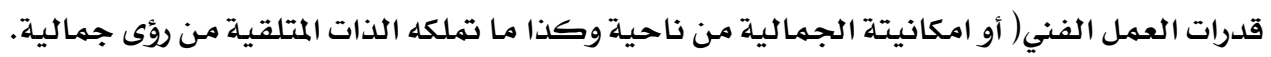

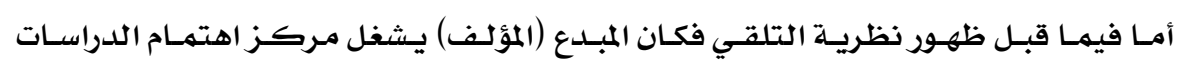

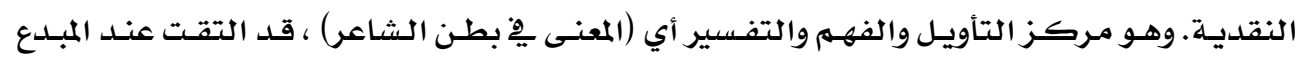

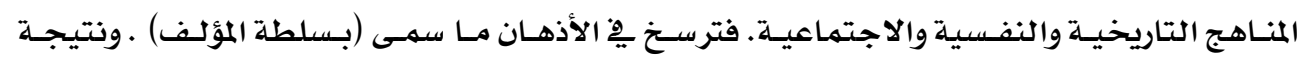

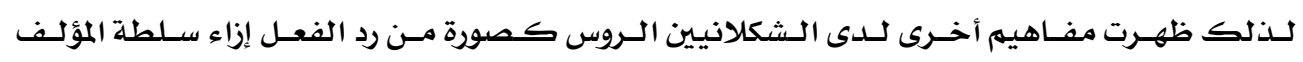

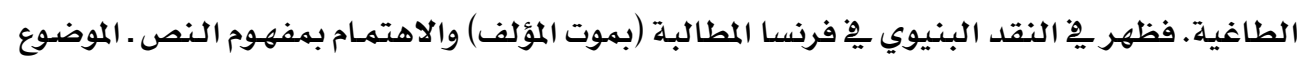

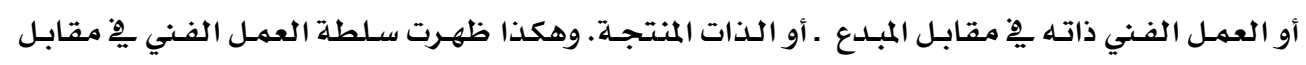
سلطة المبدع. أولهل الفئ 


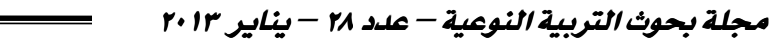

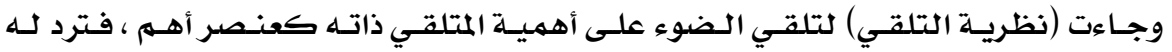

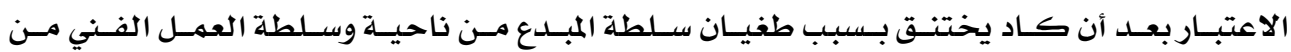
ناحية أخرى.

ولعل مـن الضروري هنا الإشـارة إلى أهم أسس ومظاهر الاختلاف بين كل مـن (يـاوس وأيـزر)،

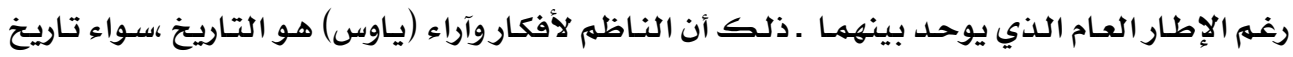

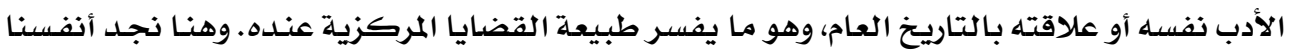

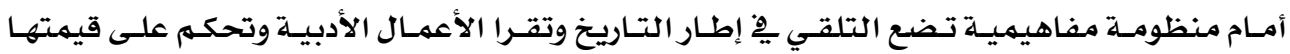

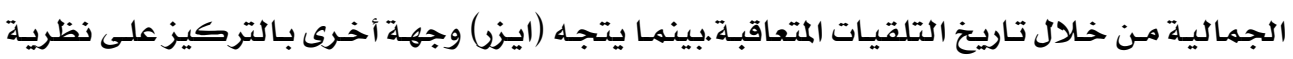

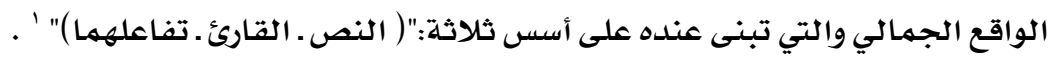

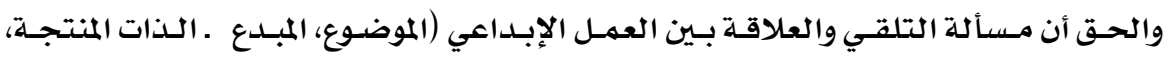

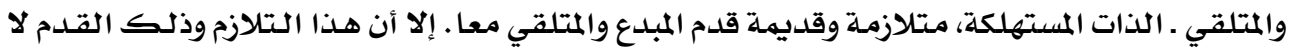

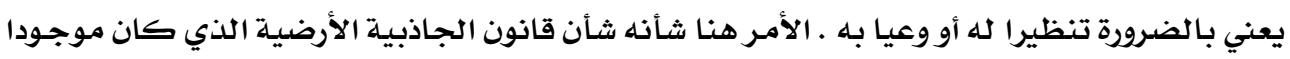

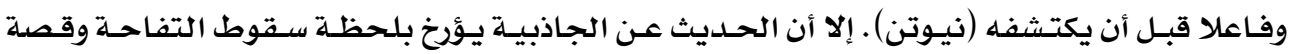
اكتشاف القانون على يد (نيوتن).

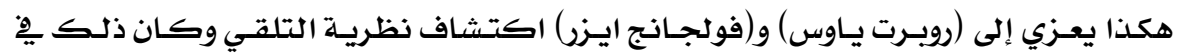

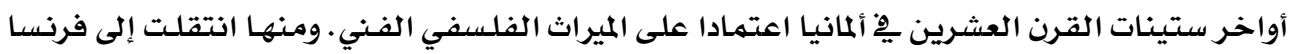
وأمريكا والكثير من دول العالهم الأخرىى.

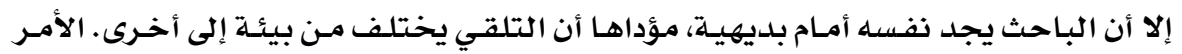

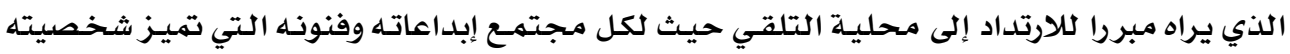

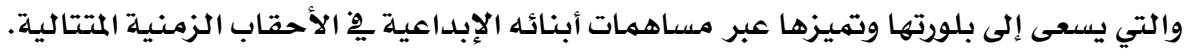

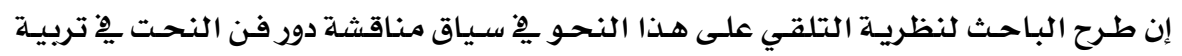

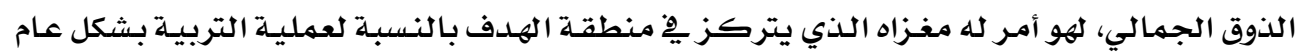

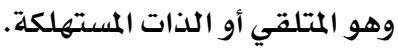

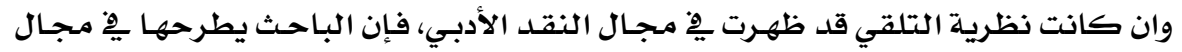

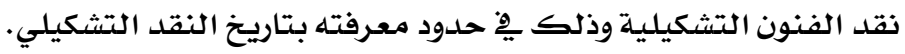

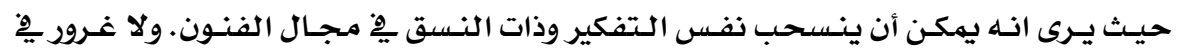

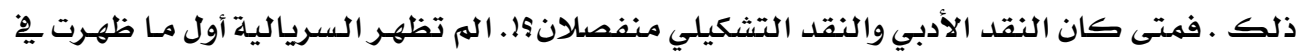

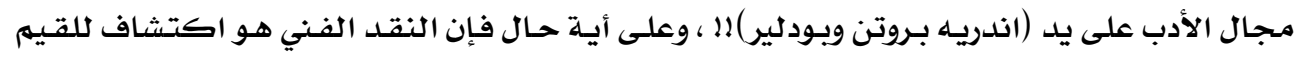

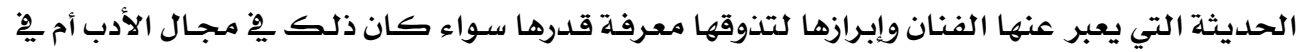
مجال الفن. 


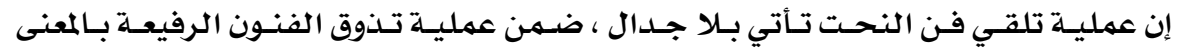

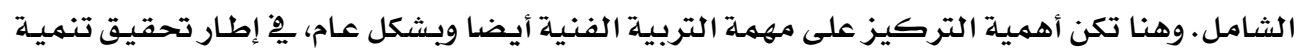

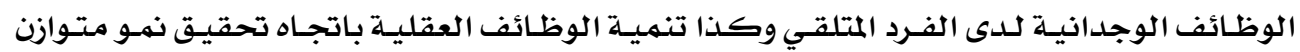

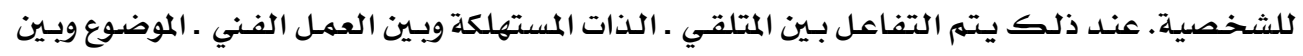
المبدع والذات المنتجهة.

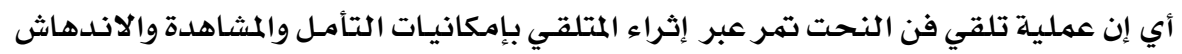

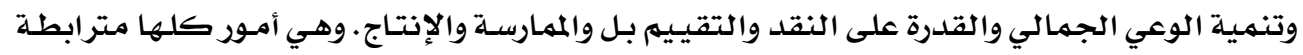

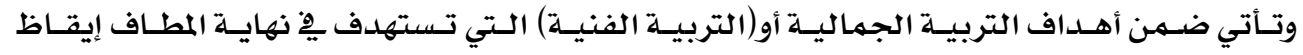

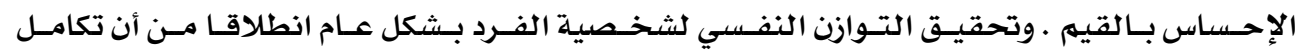

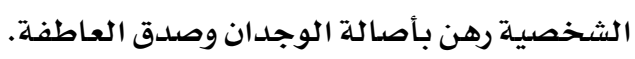

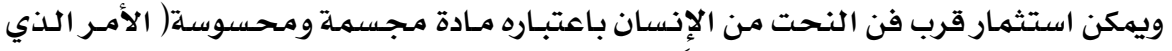

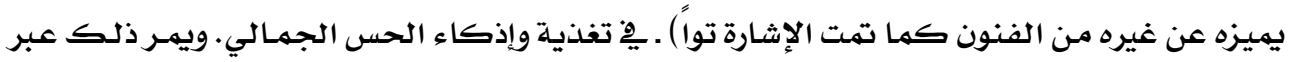

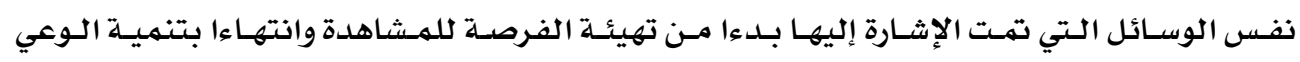
الجمالي من خلال التفاعل بين الفنان والمتلقي.

\section{خامسا: تتائج البحث وتوصياته}

\section{هِ نهاية البحث توصل الباحث إلى مجموعة من النتائج والتوصيات يسردها الباحث فيما يلي:}

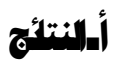

اـ إن رقي الذوق الجمالي وتطوره يتطلب تقدما وتطورا أيضا على المستوى الاجتماعي. r. إن الذوق الجمالي إنما يقوم على الإدراك العقلي والإدراك الجمالي معا

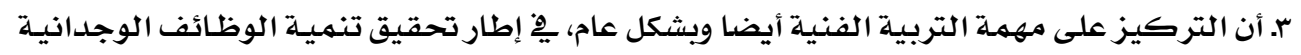

$$
\text { لدى الفرد المتلقي. }
$$

ع. إن عملية تلقي فن النحت تأتي بلا جدال، ضمن عملية تذوق الفنون الرفيعة.

\section{ب.التوصيات}

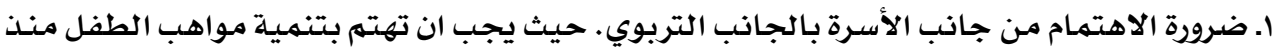

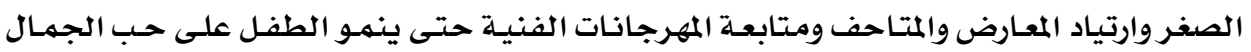

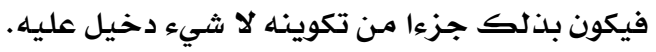

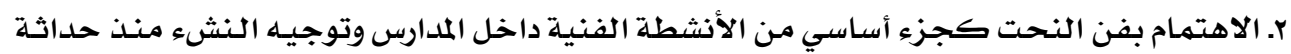

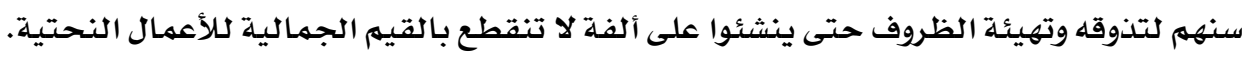




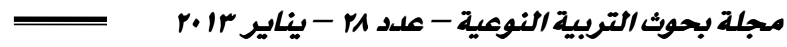

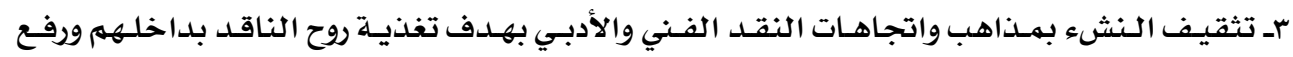

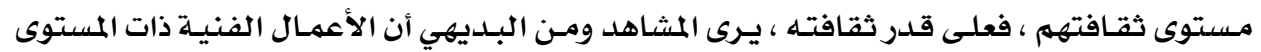

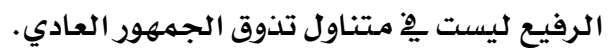

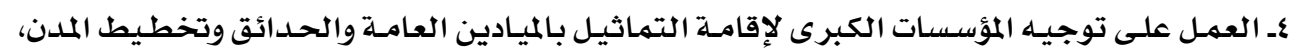

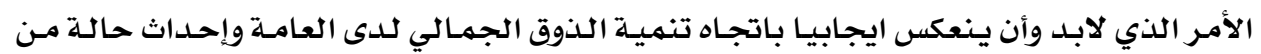

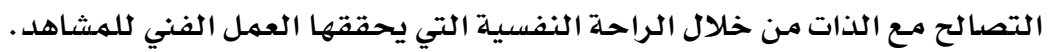

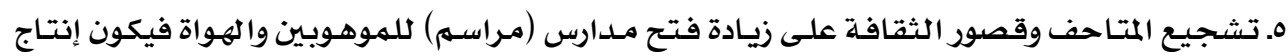

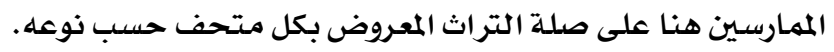
ז. العمل على تكرار التجارب والمهرجانات الفنية الناجحلة الخاصدة بفن النحت والمتمثلة يِّ سيمبوزيوم

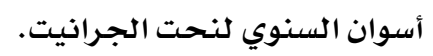

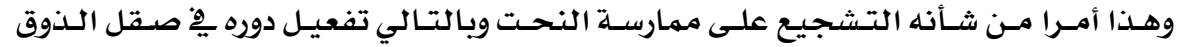

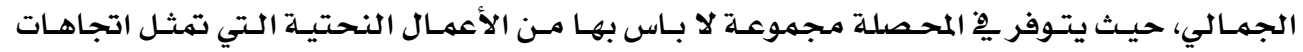

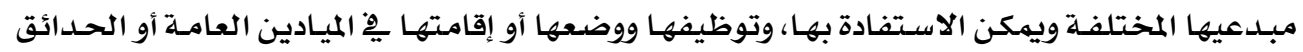

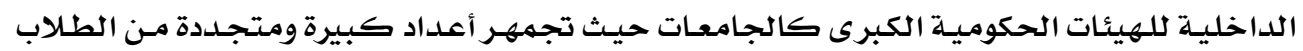

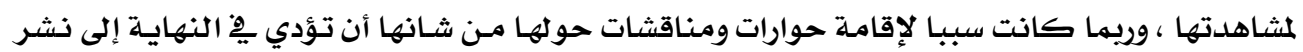

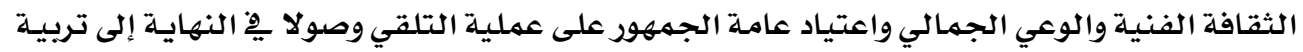

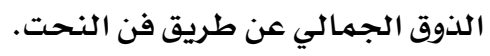


1- جورجبلينحانوف: الفنوالتصوير المادي للتحاريخ ترجمـة جورج طرابيشي - كار الطليعة للطباعةوالنشر بيروت

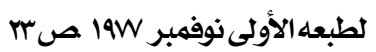

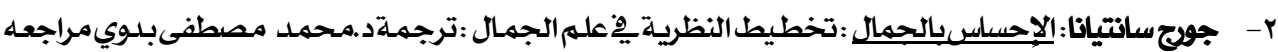
وتقليمدزنكي نجيب محمود +الهيئة المصرية العامة للكتابسنة ا..r .صره.

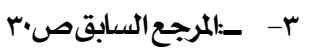

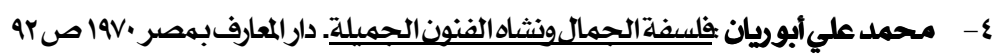

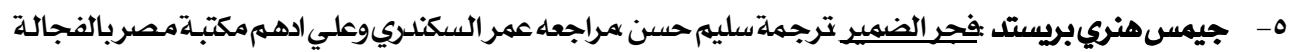
0 - 194.

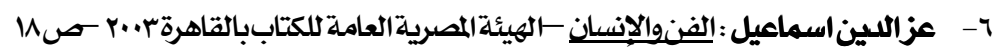
- - زكريا إبراهيم : الفنان الإنسان مكتبة غريب

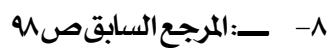

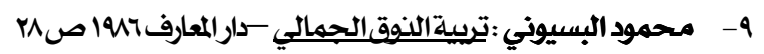

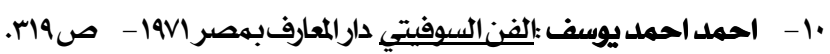

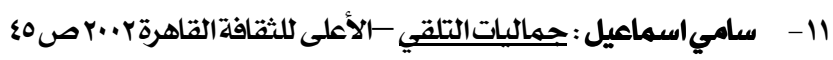
rا - عبد العزيزطليمات :فعل القراءةبناء المعني ويناء الذات.دراسةضيمن كتاب : نظرية التلقي إثكالياتوتطبيقات.

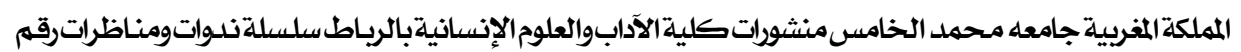

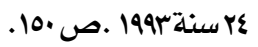




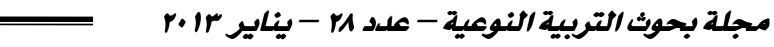

هلاحق البحث

هنتارات هن الأممال النمتية التي تمثل اتجاهات النمت في العصور المختلفة

\begin{tabular}{|c|c|c|c|}
\hline الموضوع & رقماششكل & الموضوع & 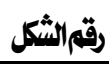 \\
\hline 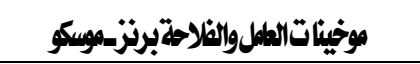 & v & 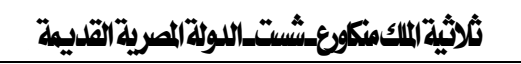 & 1 \\
\hline براكوزي_القبالة_حجر & $\wedge$ & شيخالبلاتخشبجميز-اللولة|لالصرية اتقديهة & r \\
\hline كييا ككوف_اشاعرواياكوفنكي-بروتزتموسكو & 9 & 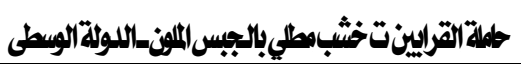 & $r$ \\
\hline سيلرة الشمس_-معلن-(انمانيا & 1. & 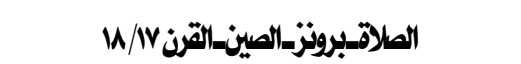 & $\varepsilon$ \\
\hline 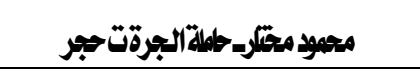 & 11 & يكلانجلو_الرحمة_مرور & 0 \\
\hline كمالـعبيلـوجه مصرية_طينمحروق ملهن & ir & هنريهوزالأموالمطل-هبر & 9 \\
\hline
\end{tabular}




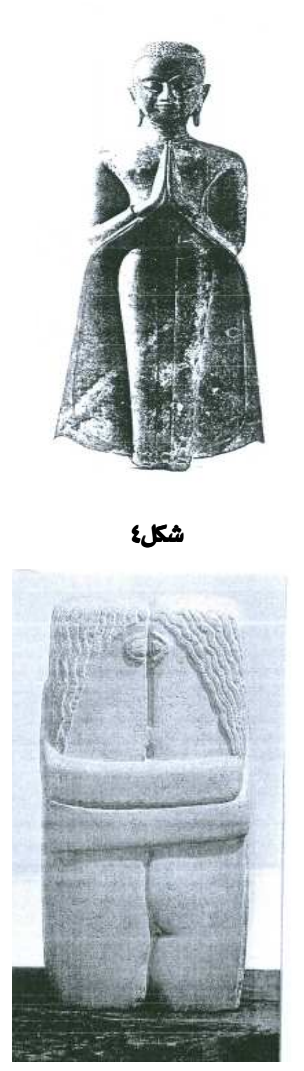

شאل

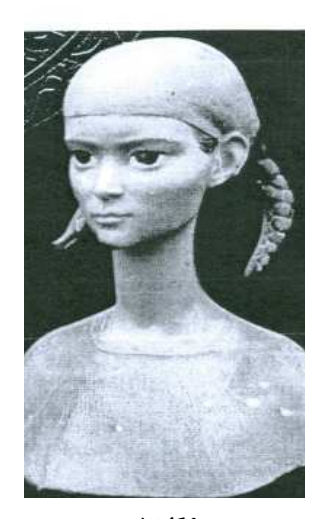

شكلri
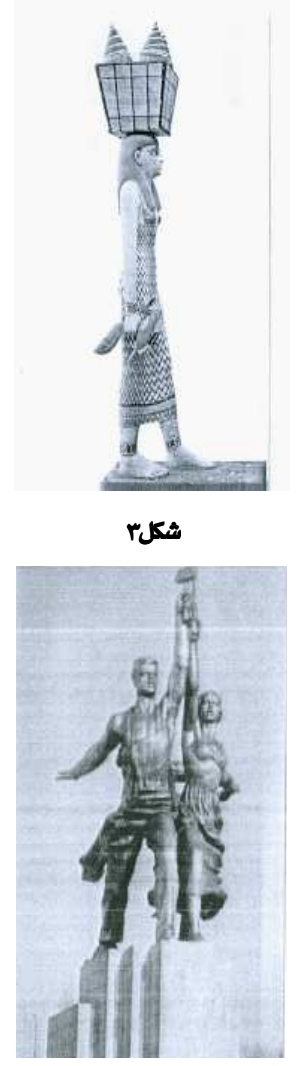

شكلv

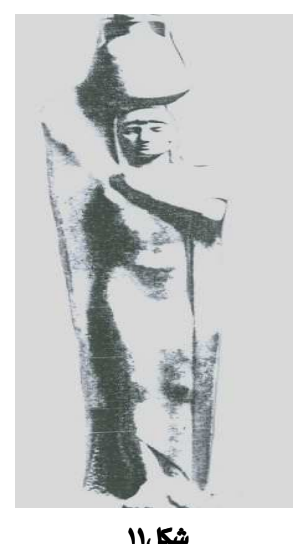

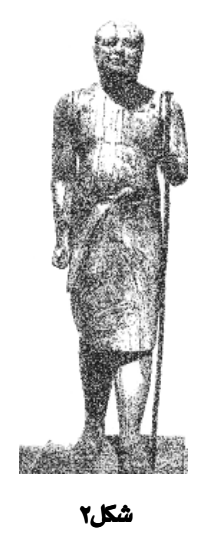
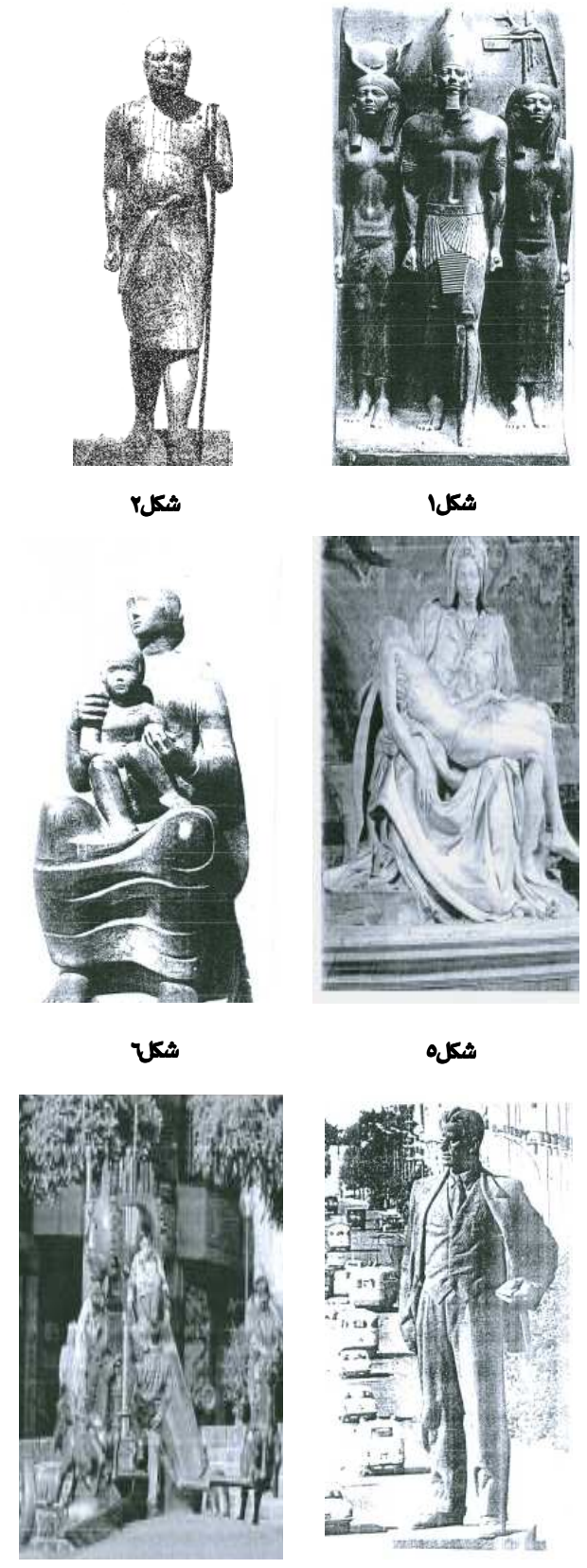

شكله

شكل.1

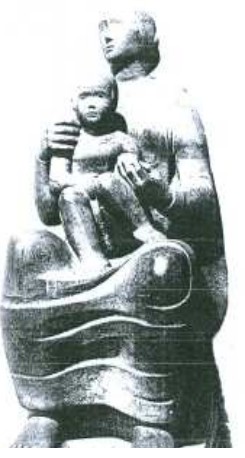

شكل

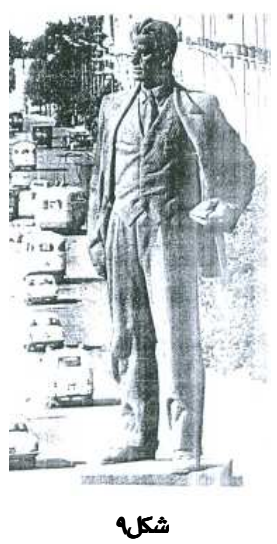

